\title{
Libertad de pensamiento, libertad de expresión, libertad de prensa: trinomio a debate
}

\author{
Rosario DE MATEO PÉREZ \\ Universitat Autònoma de Barcelona \\ Rosario.DeMateo@uab.cat
}

Recibido: 14 de mayo de 2014

Aceptado: 4 de noviembre de 2014

\begin{abstract}
Resumen
Los países occidentales son deudores de las libertades políticas y económicas instauradas en el siglo XVIII, por Francia, Estados Unidos y Gran Bretaña, entre las que se encuentran la libertad de pensamiento, de expresión y de prensa. En este texto se presenta una breve revisión de los orígenes y evolución de estos conceptos, para centrarse después en los elementos del entorno actual que están condicionando su interpretación y vigencia. El desarrollo de la tecnología digital, la mal llamada globalización y la crisis económica en los países desarrollados plantean nuevos límites a estas libertades, comprometiendo el papel de los medios de comunicación y el periodismo en la construcción social de la realidad. El análisis considera la libertad de pensamiento como requisito previo para la existencia de libertad de expresión, siendo la libertad de prensa un derecho colectivo corolario de los dos anteriores.

Palabras clave: libertad de pensamiento, libertad de expresión, libertad de prensa, crisis, periodismo.
\end{abstract}

\section{Freedom of thought, freedom of speech, press freedom: a trinomial for debate}

\begin{abstract}
Western countries are indebted to the political and economic freedoms put in place in the eighteenth century by France, the United States and Britain, among which are freedom of thought, speech and press. In this paper a brief review of the origins and evolution of these concepts is presented, and then focuses on the elements of the current environment that are affecting their interpretation and enforcement. The development of digital technology, the so-called globalization and the economic crisis in developed countries pose new limits to these freedoms, compromising the role of the media and journalism in the social construction of reality. The analysis considers freedom of thought as a prerequisite for the existence of freedom of speech, with press freedom being a collective right corollary of the previous two.
\end{abstract}

Keywords: freedom of thought, freedom of speech, press freedom, crisis, journalism.

\section{Referencia normalizada}

DE MATEO PÉREZ, Rosario (2015): "Libertad de pensamiento, libertad de expresión, libertad de prensa: trinomio a debate". Estudios sobre el Mensaje Periodístico. Vol. 21, Núm. 2 (julio-diciembre), págs.: 1017-1030. Madrid, Servicio de Publicaciones de la Universidad Complutense.

Sumario: 1. Introducción. 2. Origen de los conceptos: libertad de pensamiento, libertad de expresión, libertad de prensa. 3. Evolución posterior de la libertad de expresión y de la libertad de prensa. 4. Entorno actual y límites a las libertades de pensamiento, de expresión y de prensa; 4.1. La crisis de la Sociedad de la Información; 4.2. Cambios en la industria de los medios de comunicación; 4.3. Cambios en el periodismo; 4.4. Límites a la libertad de pensamiento y, su corolario, la libertad de expresión; 4.5. Límites a la libertad de expresión y, su corolario, la libertad de prensa. 5. Referencias bibliográficas.

\section{Introducción}

Las relaciones entre el Estado y las libertades de pensamiento, prensa e información han variado a lo largo de los dos últimos siglos y medio dependiendo del contexto político, económico y social en que han tenido lugar, oscilando entre dos extremos: la censura previa y el liberalismo sin trabas de hecho o de derecho. 
Los países occidentales son deudores de las libertades políticas y económicas instauradas en el siglo XVIII, por Francia, Estados Unidos y Gran Bretaña. Por ello, en este texto, se hará una sucinta referencia, en primer lugar, a esos antecedentes y su posterior desarrollo para, finalmente, centrarse en el entorno actual definido, principalmente, por el desarrollo de la tecnología digital, la mal llamada globalización y la crisis económica iniciada, en 2007, en los países desarrollados y que aún sigue su curso.

La premisa de la que se parte es que no han cambiado, ni han quedado anticuados, los conceptos de libertad de pensamiento, libertad de expresión y libertad de prensa, sino que han variado las circunstancias del contexto actual en el que se encuadran y, por tanto, la forma de interpretarlos por parte del poder político y económico que puede limitar la construcción social de la realidad, en la que los medios de comunicación, y los periodistas en particular, deberían ser actores independientes e imprescindibles.

\section{Origen de los conceptos: libertad de pensamiento, libertad de expresión, li- bertad de prensa}

El proceso hacia el reconocimiento de las libertades individuales iniciado en el Renacimiento, culminó en la Revolución Francesa, en la independencia de Estados Unidos y en el liberalismo político y económico de Gran Bretaña, a finales del siglo XVIII. Esos cambios políticos, económicos y sociales propiciaron la afirmación de los derechos individuales de pensamiento y expresión como 'derechos naturales del hombre', al mismo tiempo que se iniciaba el proceso de expansión de la prensa escrita.

La Declaración de los Derechos del Hombre y del Ciudadano de la Asamblea Constituyente francesa de 1789, precedente de la Constitución de 1791, establecía ya, en su artículo 11, que "la libre comunicación de sus pensamientos y de sus opiniones es uno de los derechos más preciados del hombre".

En Estados Unidos, la Declaración de Independencia de 1776, de las trece colonias, instauró, aunque sólo para los blancos, los derechos inalienables de las personas y la soberanía popular. En 1779, en su artículo 12, la Declaración de Derechos del Estado de Virginia enunciaba la libertad de prensa que recogió, después, la Constitución estadounidense de 1787. La mayoría de los autores han explicado la Primera Enmienda como un instrumento de liberalismo clásico, en cuanto que garantiza la libertad de expresión poniendo el acento en valores sociales, aunque también en el interés individual, protegiendo así la soberanía popular. En definitiva, en esa Primera Enmienda se establece que el "Congreso no hará ninguna ley... que restrinja la libertad de expresión o de prensa" declarando, así, el principio liberal clásico según el cual deben limitarse los poderes del Estado (Fiss, 1996).

En Gran Bretaña, confluyeron el liberalismo político, que estableció la opinión pública como centro político, mediatizada por la prensa, y el liberalismo económico, eje rector de la Revolución industrial, comenzada en este país y cuyo inicio, diversos autores, sitúan en momentos distintos: J.U. Nef, a finales del siglo XVII; Arnold J. Toynbee, en 1760; y otros autores, como WW Rostow, en la década de 1780. 
Los fundamentos del liberalismo político del siglo XVIII, están construídos sobre un individualismo radical del ser humano, cuyas libertades están garantizadas por la justicia y las leyes que establecerán los límites del poder y la soberanía popular.

De esos fundamentos nació el concepto de mercado que, finalmente, se completó con el de la 'mano invisible' de Adam Smith, en 1776, haciendo recaer, así, la organización social en el intercambio mercantil, a través de la libertad de empresa. Esta filosofía liberal, queda definida sin matices en el siguiente párrafo de su obra La Riqueza de las Naciones: "El hombre reclama en la mayor parte de las circunstancias la ayuda de sus semejantes y en vano puede esperarla sólo de su benevolencia. La conseguirá con mayor seguridad si se dirige a su interés personal y les hace ver que es ventaja para ellos hacer lo que les pide. Así lo hace quien propone al otro un trato cualquiera: Dame lo que necesito y tendrás lo que deseas es el sentido de cualquier clase de oferta, y así obtenemos de los demás la mayor parte de los servicios que necesitamos. No es la benevolencia del carnicero, del cervecero o del panadero lo que nos procura el alimento, sino la consideración de su propio interés. No invocamos sus sentimientos humanitarios sino su egoísmo, ni nunca les hablamos de nuestras necesidades sino de sus ventajas" (A. Smith, 2004: 404).

Pero, lo que los neoliberales olvidan de forma interesada, denominándose sus descendientes, es que Adam Smith, economista pero también filósofo moral, matiza ese liberalismo a ultranza al considerar que "sólo es buen ciudadano el que está dispuesto a respetar las leyes. Indudablemente, es un buen ciudadano aquel que acaricia el deseo de fomentar el bienestar de la comunidad entera con todos los medios que tiene a su disposición" (A. Smith, 1999: 95)

\section{Evolución posterior de la libertad de expresión y de la libertad de prensa}

Desde el siglo XVIII, en los países occidentales ha existido la necesidad de encontrar un equilibrio entre dos intereses en conflicto: la libertad de expresión pública y los intereses del Estado. La libertad de expresión como facultad de expresar lo que se quiera por medio de impresos, primero, luego por otros medios de comunicación, sin censura previa, se ha de sujetar a las leyes. Por tanto, ahí hay un campo de controversia que se ha manifestado en, prácticamente, todas las épocas posteriores al nacimiento del liberalismo del que pronto surgieron dos corrientes: Una, que consideraba al Estado como mero vigilante, sin apenas intervención en los asuntos de la sociedad; otra, para la que el Estado era árbitro indispensable en los conflictos, con el fin de garantizar los derechos y las libertades individuales y sociales como principio del progreso.

$\mathrm{Y}$ ahí cabe recordar la injerencia de todos los Estados en la libertad de prensa, en momentos diversos. En países democráticos, en tiempos de extrema necesidad, como por ejemplo las guerras, dos mundiales en el siglo XX. O por la intención de algún político de controlar a la prensa como sucedió, por ejemplo, con el presidente Nixon, en Estados Unidos, país que se reclama liberal por excelencia, a principios de los años setenta del siglo XX. Desde finales del siglo XVIII, la prensa liberal sufrió la mayor ofensiva contra su libertad al tratar de impedir, en 1971, la publicación de los llamados 'papeles del Pentágono' convirtiéndose, así, en el primer presidente estadounidense que trató de ejercer abiertamente la censura. En 1972, se destapó el Watergate, decisivo para el impeachment de Nixon en 1974. 
En países dictatoriales, los Estados han ejercido la censura previa como sucedió, por ejemplo, en los países del llamado socialismo real. En España, la controversia y la censura fueron señas de identidad de casi toda la andadura de la prensa escrita desde el siglo XVII, en que apareció la primera publicación diaria, Gaceta de Madrid, en 1661. Hubo un intento de adaptar la legislación liberal de Francia en la Ley de Prensa de 1889 , pero hubo tantos momentos de excepción, en los que se ejerció la censura, que apenas se pudo considerar la vigencia de la libertad de prensa.

Durante el franquismo, la Ley de Prensa e Imprenta de 1966 proclamó las libertades de expresión y de empresa en los artículos 1 y 16, respectivamente, la segunda recortada y la primera eliminada en los supuestos recogidos en otros artículos.

En España, para la empresa periodística, el principio del fin de la transición se encuentra en el texto de la Constitución de 1978. En ella se consagran la libertad ideológica (artículo 16), la libertad de expresión (artículo 20) y la libertad de empresa (artículo 38). Pero este período transitorio no terminará hasta 1984, año en que se derogaron las restricciones impuestas por la Ley de 1966 para la creación de este tipo de empresas.

Pero, además, la conjunción del liberalismo político y económico hizo posible el desarrollo de la prensa escrita, a finales del siglo XIX pero, sobre todo a principios del $\mathrm{XX}$, en que la producción y el consumo de masas propició la rápida evolución de la publicidad que ha desempeñado, a partir de entonces, un papel fundamental en la rápida integración de los periódicos en los circuitos del mercado. Así, son igualmente válidos, para todos los países occidentales, los siguiente comentarios sobre la prensa británica, realizados por Raymond Williams a principios de los años setenta del siglo XX: "La propiedad de los medios de comunicación, viejos y nuevos, ha pasado o está pasando a una especie de organización financiera desconocida en etapas precedentes, y con unas características específicas que se asemejan a las principales formas de propiedad que la producción industrial genera. Los métodos y las actitudes de los negocios capitalistas se han establecido en el mismo centro de las comunicaciones" (Williams, 1974: 31-32).

Ahí comienza, sobre todo en Europa Occidental, el proceso hacia el predominio del aspecto económico del concepto de información que dará lugar, posteriormente, al olvido paulatino del aspecto de servicio de interés público. Esta consideración de la información periodística como mercancía, puede representar un límite a la libertad de prensa ya que "la libre fundación de empresas queda de hecho reducida a la libertad de unos pocos: quienes poseen los medios económicos necesarios para emprender una tarea semejante" (Conesa, 1978: 318).

Así, en el siglo XX, al equilibrio entre la libertad de expresión y los intereses del Estado, se ha sumado, de forma clara, la necesidad de equilibrio entre el poder político y económico ya que el mercado, por sí solo, no garantiza estabilidad alguna. Y, además de la libertad de prensa, se ha de garantizar el derecho a la información, evocado por muchos autores, después de que el Papa Juan XXIII lo expresara en su encíclica Pacem in terris de 1963 que, entre otros, contempla el derecho de acceso al ciudadano a los ficheros de la administración que le conciernen (Chamoux, 1994: 5) 
Por dejar el funcionamiento del mercado sin la necesaria y suficiente dirección política, se han producido crisis económicas con graves secuelas sociales. Así sucedió, por ejemplo, con la crisis económica de 1929 que propició el ascenso de Hitler al poder; con la crisis económica de los años setenta del siglo pasado, que abrió el proceso hacia el neoliberalismo y un nuevo modelo de crecimiento e intercambio que, finalmente, sufrió otra gran crisis, iniciada en 2007, en los países desarrollados.

Únicamente la economía capitalista gozó de estabilidad durante la época del llamado Estado del Bienestar, instaurado después de la Segunda Guerra mundial, sobre todo en Europa occidental, porque el poder político tuvo un papel activo tratando de equilibrar al poder económico.

\section{Entorno actual y límites a las libertades de pensamiento, de expresión y de prensa}

La crisis de las empresas de medios de comunicación y, en particular, las editoras de prensa en papel, se hizo patente con la crisis económica iniciada en 2007 y aún no finalizada. Sin embargo, esta crisis empresarial ha repercutido, negativamente, en el periodismo y su función social en la "democracia de mercado", según expresión de Brückner (2002: 164). Y, dicha crisis del periodismo no es achacable solamente a la crisis económica, sino que se venía gestando durante los años de alta rentabilidad y altas remuneraciones en los principales medios de comunicación.

Crisis económica, crisis de las empresas de medios comunicación, principalmente las empresas periodísticas, $\mathrm{y}$, en consecuencia, crisis de la libertad de pensamiento, de la libertad de expresión y de la libertad de prensa.

\subsection{La crisis de la Sociedad de la Información}

La crisis industrial, monetaria y petrolera, de finales de los sesentas y principios de los setentas del siglo pasado, significó el principio del fin del modelo de crecimiento e intercambio nacido después de la Segunda Guerra mundial y liderado por Estados Unidos (De Mateo y Bergés, 2010: 77).

A partir de ese momento, se comenzó a preparar el terreno para hacer posibles los cambios en los procesos productivos que llevaran a un mayor crecimiento e intercambio económicos. Los gobiernos de Margaret Thacher y de Ronald Reagan, los organismos económicos internacionales y las compañías multinacionales hicieron renacer la primera corriente originada por el liberalismo, antes citada. Esto es, el Estado como mero vigilante, que sólo intervendría para facilitar y garantizar el funcionamiento libre del mercado como regulador de la economía, cuya reforma estaría basada en la obtención del máximo beneficio, sin consideraciones sociales de tipo alguno, en detrimento de una reforma para una economía más sostenible.

Ese proceso se concretó, en 1991, en un nuevo modelo de crecimiento económico llamado de maneras diversas y conocido, en terminología aceptada casi universalmente, como Sociedad de la Información, centrado en el terreno económico y no en el social. En él, el crecimiento económico y el intercambio tienen su base principal en el sector servicios, en el que van a tener un papel decisivo las tecnologías de la información y la comunicación para obtener una mayor productividad en el mercado mun- 
dial, caracterizado por la liberalización, la desregulación, la privatización de empresas públicas y la competitividad internacional. En dicho sector servicios se encuentran, entre otras industrias, la financiera, las telecomunicaciones, la audiovisual y, por extensión, más tarde, la de todos los medios de comunicación que entraron, así, en el estatuto industrial dominante.

Ese modelo se ha basado en dos principios básicos: en una reglamentación flexible que ayude a la convergencia tecnológica para incrementar la productividad de las empresas, que les permita hacer suficiente acumulación de capital para que puedan actuar en un mercado globalizado; y en el papel del mercado, cuyas reglas ordenarán el funcionamiento de las diferentes industrias y empresas, y cuyo caso más extremo se da, incluso en la crisis actual, en el sistema financiero, totalmente globalizado y sin regulación alguna, y que ha sido actor fundamental en enmascarar las limitaciones de este modelo de crecimiento. Así, ayudó a la salida rápida de las crisis económicas de 1993 y de 2001, gracias a los préstamos a hogares y empresas para consumir e invertir, respectivamente, haciendo crecer la economía a base de endeudamiento, con fondos que las entidades financieras cubrían con otros fondos demandados a otras entidades financieras. Hasta septiembre de 2007, en que se inició la crisis con el tema de las hipotecas basura y continuó con las posteriores crisis bancarias, iniciadas en Estados Unidos y seguidas por otros países desarrollados, con pérdida de la confianza entre los bancos y, por extensión, entre la mayoría de instituciones.

En España, la crisis financiera y económica será larga, por ser una economía muy dependiente del exterior en energía y en capital, y por tener un modelo de crecimiento basado en industrias de baja productividad, bajo valor añadido, e intensivas en factor trabajo: turismo, construcción y automóvil, fundamentalmente. Dos problemas sin resolver: la elevada tasa de paro, sin solución posible a corto y, tal vez, a largo plazo; y la deuda, que podría ser origen de una burbuja financiera.

Las empresas de medios de comunicación, aunque más tardíamente, se insertaron en ese modelo viéndose, sobre todo las empresas dominantes, inmersas en procesos de crecimiento acompañado por la liberalización, la privatización, la concentración y la internacionalización, hasta que entran en el túnel de la crisis, a partir de 2008, y con más intensidad las empresas de prensa escrita.

En ese complejo contexto hay que encuadrar, desde la década de los noventa del siglo pasado, el proceso de transformaciones en la industria y en la gestión de los medios de comunicación.

\subsection{Cambios en la industria de los medios de comunicación}

El continuado desarrollo de las tecnologías de la información y de la comunicación, basado en su convergencia, ha ido modificando, tanto las posibilidades de creación y producción, como de distribución y recepción de contenidos y, por tanto también, de información periodística.

La introducción de Internet y de otros dispositivos volvió a resucitar a los apocalípticos e integrados de Umberto Eco, pues es lo que suele suceder con todas las innovaciones técnicas que, según un autor, se desarrollan en tres tiempos: "el de los fantasmas y las psicosis, el de la experimentación y el de la banalización (Marciolla, 2000: 246). 
La introducción de esas tecnologías, sobre todo, ligadas a la moda de los emprendedores, lanzada por el gobierno español y secundada por la Generalitat de Catalunya, con el altavoz de los medios de comunicación, ha creado expectativas exageradas, fundamentalmente, en dos casos: Por un lado, en los cambios del producto informativo; por otro lado, en la posibilidad de convertir al periodista en empresario, lo que sería una solución en épocas de crisis como la actual para tratar de resolver el paro y la precariedad laboral.

En el primer caso, las tecnologías han sido tratadas como entes autónomos sin tener en consideración que son, simplemente, un factor de producción que cada empresa adaptará a sus procesos productivos para aumentar su productividad $\mathrm{y}$, en definitiva, su rentabilidad empresarial, al hacer llegar a los ciudadanos los contenidos de información, sea en el formato que sea. En otras palabras, como dice un autor, en el periodismo digital "los elementos de la narración clásica -planteamiento, nudo y desenlace- han dado paso a las formas fragmentadas marcadas por la bifurcación y la ramificación. Ahora el relato es multilineal, multisecuencial y multifacético, con grandes cantidades de información enlazadas que permiten numerosos itinerarios al usuario. Pero la técnica del periodismo tiene que aplicarse para elaborar una información veraz, precisa, rigurosa y amena. Se necesitan los datos, la invención -creación-, la composición - disposición-, el estilo y la difusión. Lo básico persiste y convive con lo nuevo, el hipertexto" (López, X.). Es decir la esencia del periodismo no cambia con el periodismo digital. La tecnología incorpora al trabajo periodístico nuevas formas de documentación y de selección y relación con las fuentes y la forma de presentación de la información, pero no el contenido. ¿Acaso el periodista no se enfrenta ahora a parecidos retos en la selección de temas, búsqueda de fuentes y creación de discursos, ahora con nuevas herramientas?

En el segundo caso, no es fácil el acceso a la actividad empresarial en el periodismo. Entre otras razones, porque la crisis de la industria de medios de comunicación puede calificarse como una crisis de sobreproducción después de dos décadas de expansión de los mercados de la comunicación. Al incremento de la oferta en los medios tradicionales se ha añadido la aparición de nuevos medios digitales, lo que se ha traducido en una amplia oferta en la que concurren muchos medios de comunicación en competencia unos con otros. En una parte importante este crecimiento ha sido impulsado por las mismas empresas de medios tradicionales, que han seguido estrategias de crecimiento empresarial multimedia, horizontal, vertical y en conglomerados. Además, la mayor parte de esas empresas ofrecieron sus diarios digitales gratuitamente lo que ha hecho que haya también una saturación de información y que el consumidos no esté dispuesto a pagar por ella, a no ser que tenga importante valor añadido. Pero, también, por la entrada de nuevos actores, en competencia con las empresas de medios de comunicación, especialmente en los nuevos mercados digitales, donde éstas convergen -compitiendo y cooperando- con multinacionales de las telecomunicaciones y las tecnologías de la información y la comunicación (De Mateo y Bergés, 2010: 82).

Va en aumento un fenómeno que empezó a visibilizarse en 2010: que la industria de medios de comunicación, es decir los medios convencionales, lentos en su adap- 
tación y culturalmente más atados al contenido que a la tecnología, están perdiendo el liderazgo en la creación de negocios en ese nuevo entorno. Así se habla ya de periódicos ubicuos que surgen de los acuerdos entre los productores de contenido periodístico como, por ejemplo, The New York Times, y las mayores empresas tecnológicas, como Facebook, las cuales, desde 2011, comenzaron a moverse rápidamente en la consolidación de su poder para devenir en fabricantes de 'todo'en la vida de los consumidores. Todo ello conduce a las siguientes preguntas: ¿Será posible hallar modelos de negocio que permitan crear diarios digitales que puedan competir con los medios tradicionales? Hay algunos ejemplos, pero no suficientes para poder afirmarlo; ¿Bastará con dar información con poco valor añadido?; ¿los gigantes tecnológicos -Google, Amazon, Facebook, Apple y pocos más- se harán finalmente con el legado de marcas de información como parte del 'todo' que ofrecen a sus consumidores? ¿es posible competir con los grandes grupos de comunicación, editores de diarios? ¿Sobrevivirán las pequeñas y medianas empresas editoras de diarios?

En las casi tres últimas décadas, la expansión de la industria de la comunicación española ha implicado un cambio en el 'modelo de negocio', desde las empresas 'familiares' de prensa con una producción integrada cuya financiación se basaba en las ventas de ejemplares y de publicidad, a empresas multimedia de comunicación, con una producción cada vez más externalizada y mucho más dependientes de los ingresos publicitarios y de los recursos externos. En los años noventa, el lanzamiento, con pérdidas, de la televisión privada contó con los recursos financieros de los grandes grupos de comunicación europeos y de los bancos españoles. Más tarde, las plataformas de pago por satélite y cable contaron con el apoyo financiero de bancos y entidades de inversión, así como de compañías multinacionales y de otros sectores de actividad (eléctricas, construcción...) que formaron parte del capital social de las plataformas. La prensa gratuita para grandes ciudades se introdujo gracias al apoyo financiero de los fondos de inversión internacionales. Las grandes empresas de medios de comunicación realizaron también su salida a bolsa para captar más recursos financieros y mejorar la rentabilidad para los grandes accionistas. Esas empresas optaron, también, en muchas ocasiones, por el endeudamiento para mejorar la rentabilidad del capital, gracias al apalancamiento (De Mateo, Bergés y Garnatxe, 2011: 119).

Todos esos cambios en el contexto político-económico y en los mercados e industrias de la comunicación han afectado, lógicamente, a las formas de hacer periodismo y a la propia situación del periodismo en el sistema de comunicación y en el sistema social. Algunos de los protagonistas del proyecto globalizador y de la crisis de la Sociedad de la Información figuran en el centro del entramado mediático, ya sea como accionistas y administradores, como acreedores $\mathrm{u}$ otros proveedores de fondos externos, o como anunciantes (De Mateo y Bergés, 2010: 97).

\subsection{Cambios en el periodismo}

Los cambios en el mercado publicitario y en el reparto de audiencias presionan sobre la definición de unos productos -los contenidos de los medios de comunicación-cada vez más atentos a los estudios de mercado. El gasto en producción se optimiza para obtener la máxima productividad con contenidos que generen audiencia y publicidad. 
Las estrategias de marketing, de producción y de financiación de las empresas de comunicación suponen, pues, nuevas tensiones sobre el modelo de periodismo en la economía neoliberal.

Durante años, la información e incluso el entretenimiento, a través de los medios de comunicación, fueron considerados $-\mathrm{y}$, en algunos casos, aparentemente, aún lo son- un bien de servicio público. La situación cambió con la liberalización de la televisión, que reforzó los argumentos económicos en la gestión de los medios de comunicación. En este contexto de mercantilización de la información y del periodismo, la sobreoferta de contenidos hace más difícil para las empresas la competencia en el mercado de la comunicación. Ello conlleva buscar fórmulas para llegar a más audiencia y reducir gastos para, así, poder rentabilizar las inversiones, aunque sea a costa de trivializar y menguar parte de la calidad del producto.

Así los medios de comunicación social han ido perdiendo parte de su función social, al estar más preocupados por alcanzar los máximos beneficios posibles y una cuota de poder político y económico. Por ejemplo, los periódicos diarios, por sus intereses políticos -concesiones, subvenciones, publicidad institucional- y económicos, no ofrecen -salvo en ocasiones- una información diferencial de calidad, ni gozan de independencia informativa.

Las tendencias económico-políticas y sociales de los últimos años han llevado a casi todos los medios de comunicación a un cierto grado de dependencia. Cabe destacar tres tipos de falta de independencia que condicionan, y mucho, los contenidos que ofrecen los medios:

- financiera (¿cómo debe un medio de comunicación informar de la actual crisis o de conflictos que afecten a un determinado banco, por ejemplo, Santander-caso Botín por fraude fiscal-o a determinado anunciante-Telefónica, por ejemplo);

- política, a nivel estatal y autonómico, (reparto de licencias, política de comunicación, legislación, publicidad institucional);

- la de los periodistas, pues los recortes en los presupuestos empresariales y la amplia oferta de profesionales han sido asociados a un elevado nivel de precariedad. Junto con la creciente tendencia a informar con la mayor rapidez posible, esta precariedad laboral ha convertido al periodista en un gran dependiente de la información que proviene de las fuentes oficiales y de gabinetes de comunicación empresariales, y de lo que comúnmente se ha denominado periodismo de declaraciones. Este tipo de información reduce los costes de las empresas periodísticas quedando poco margen, pues, para la selección crítica, el contraste de informaciones o la investigación por parte de unos periodistas con escasos tiempo y recursos para llevarlo a cabo.

En un momento económico en que bajan los ingresos por publicidad y las ventas, -por ejemplo, en 2014, hubo un descenso generalizado de la difusión de la prensa escrita diaria, exceptuando La Razón que creció más del 30\%, aunque no es un incremento significativo pues partía de valores absolutos bajos-, se reducen costes a costa de la calidad del producto. Por ejemplo, se dedican recursos a la presentación de un 
futbolista famoso porque es una información relativamente barata de producir, mientras que se recortan para el periodismo de investigación sobre casos políticos o económicos, interesantes socialmente para la transparencia democrática.

Los medios de comunicación, ahora, inmersos en la crisis, tienden a buscar soluciones rápidas para cuadrar la cuenta de resultados. Externalizar parte de la producción les da más flexibilidad laboral, menos costes empresariales y les permite evitar, en cierta forma, los convenios colectivos o de empresa. En la mayoría de los casos, el interés económico prima por encima del interés periodístico y, por ello, optan por la reducción de plantillas con la justificación de querer ser más competitivos. Es una forma habitual de incentivar prejubilaciones en la empresa, con lo que se deja perder el aparato productivo de más experiencia, y más caro, para cubrir esas vacantes con menos personal, más barato y, en algunos casos, externo. Es una forma de empobrecer los contenidos informativos al prescindir de los profesionales con más experiencia.

La reducción del número de periodistas para el mismo trabajo deriva, en muchos casos, en el periodismo de mesa. Cada vez más muchas noticias publicadas en los periódicos son fruto de 'cortar y pegar' la información proveniente de agencias de noticias o gabinetes de comunicación que emplean mucho más tiempo y recursos en elaborar el texto que responda a sus expectativas. Se pierde, así, la capacidad crítica y de contraste de informaciones que se le supone al periodista.

No se puede olvidar que la profesión periodística ha entrado también en el túnel de la precariedad. A los despidos hay que sumarle el importante grueso de licenciados que año tras año entran en el mercado laboral. Esa sobreoferta de mano de obra para menos puestos de trabajo hace que la precariedad en el sector vaya en aumento.

El periodismo está perdiendo esa capacidad de control, de cuarto poder en democracia. Por un lado, las servidumbres de la falta de independencia de las empresas de medios de comunicación, de la precariedad laboral en el periodismo y de la propia lógica del afán de lucro en la producción periodística. Por otro lado, el cambio de posición del periodismo en el espacio público de comunicación, desde un escenario en que las empresas periodísticas y el periodismo ocupaban un espacio central en los medios de comunicación pública, a un escenario de competencia en mercados globales de la comunicación (De Mateo; Bergés; y Garnatxe, 2010: 98-102).

La capacidad de contar la realidad, de control y crítica de los abusos del poder, de garantía de la libertad de expresión y de la libertad de prensa, así como de la libertad de información, está dispersa, incluso se traslada en parte a la ciudadanía, pero el desarrollo de las diversas formas de información pública, en algunas ocasiones, puede fomentar la demagogia, el rumor y las mentiras. En este contexto de incertidumbre, la paradoja es que, aunque muchos ciudadanos critican y dicen desconfiar de los medios de comunicación, el periodismo parece cada vez más necesario en esa jungla de informaciones y, aunque la información digital cubre ciertas necesidades, según un estudio realizado por investigadores de Harvard en 2009, los consumidores aún percibían la prensa escrita en papel como la forma más deseable de recibir información (Chyi, H.I y Chang, H,C.). En la actualidad parece que sigue siendo válida, al menos en parte, esa conclusión puesto que, también, los otros medios de comunicación tienen como referencia los periódicos, sean en papel, sean digitales. 
4.4. Límites a la libertad de pensamiento y, su corolario, la libertad de expresión Como derecho individual, la libertad de pensamiento depende del libre arbitrio de cada individuo por lo que, en apariencia, no puede ser recortada ni limitada por ningún poder. Un ejemplo, relativamente reciente, fue el caso del dirigente del Congreso Nacional Africano (ANC), Nelson Mandela, condenado, por luchar contra el apartheid, a cadena perpetua de 1964 a 1990, año en que fue liberado y comenzó las negociaciones con el presidente sudafricano De Klerk para abolirlo. Finalmente fue presidente de Sudáfrica en 1994 y puso en marcha su proyecto de reconciliación nacional. La valoración entusiasta de su libertad de pensamiento debería ir más allá del individuo, pues es positiva y creadora en cuanto se inserta socialmente.

Esa es la idea que se desprende de la obra Sobre la libertad, del último representante de la Escuela clásica, J. Stuart Mill, en 1859, al considerar la inclusión de los conceptos de libertad y autonomía en la concepción del bienestar del ser humano, cuya individualidad significa que lo que es bueno para cada individuo depende de las relaciones con los demás, puesto que una parte importante del material con el que dicho individuo se va formando, a lo largo de su vida, está inmerso en el entorno social. Es decir, la libertad de pensamiento tiene como corolario la libertad de expresión.

En esta etapa de globalización y de crisis, las relaciones entre los individuos vienen explicadas, en gran parte, por las relaciones capitalistas neoliberales, contexto en el que la libertad de pensamiento se ha de ejercer sin prejuicios, con distancia crítica respecto a los poderes político y económico que pueden cercenarla. Pues, desde un punto de vista ético, no hay libertad de pensamiento sin capacidad crítica que sólo se adquiere a través del conocimiento.

El mundo está siendo inundado por una ola gigante, originaria de Estados Unidos, que trae un concepto restrictivo de la educación. Pues, sólo es válida la instrucción en aquellos conocimientos utilitarios para el mantenimiento del capitalismo neoliberal y su doctrina filosófica dominante a escala global, el utilitarismo, que considera la utilidad como principio de la moral.

La educación ha de ser entendida, según Salvador Pániker (2014), como Paideia, y está amenazada por el poder político y económico, Sin ese tipo de educación no hay conocimiento, ni libertad de pensamiento, y por ende, ni libertad de expresión. Los griegos de la época helenística entendían por Paideia la cultura en su totalidad y los latinos la tradujeron como humanitas. Esa forma de educación implica conocimiento del entorno, curiosidad por conocer lo que en el mundo sucede, tener fe en la realidad y gusto por lo difícil, por lo que cuesta esfuerzo. El individuo, así formado, construye un ego fuerte pero con desapego de las cosas, es un ser desprendido y saludable, según expresión del psicólogo y psiquiatra Carl Gustav Jung, creativo y abierto pero no optimista pues sólo puede serlo el individuo mal informado. Eso permitirá al individuo no sacralizar nada, no dejarse engatusar por nadie, ni por vocablos absolutos. En definitiva, ha de ser un individuo preparado para vivir de forma crítica en una sociedad como la actual, en la que parece haber mucha información, menos comunicación y menor conocimiento.

En España, por ejemplo, desde el inicio de la globalización, a finales de los setenta del siglo XX, los políticos han despreciado el tema de la educación como lo de- 
muestra su incapacidad, interesada o no, por firmar un Pacto por la Educación que evitara cambios continuos al socaire de los cambios de gobierno. En estos momentos, con actuaciones como las del ministro de educación Ignacio Wert, a favor de la privatización de la enseñanza que merma la posibilidad de educación, según el principio de igualdad de oportunidades, se hace patente el desprecio por el conocimiento y por lo público.

Así, por citar algún ejemplo, en la Comunidad de Madrid, en estos años de crisis, mientras la inversión en la escuela pública ha descendido alrededor del $20 \%$, en la escuela concertada, ha aumentado un 9\%. En la Comunidad Valenciana, se ha blindado el presupuesto para este último tipo de educación y ha descendido el presupuesto de la pública.

De esa forma, se está rompiendo un sistema de significado que no es producto de los individuos sino de las relaciones sociales. Así, el lenguaje se vuelve ininteligible, se conservan los términos de siempre pero ya no se sabe lo que significan. Es el reinado de los eufemismos que ayudan a no llamar a las cosas por su nombre, lo que explica la desconfianza de los ciudadanos en el funcionamiento de la política y de la economía.

La globalización, como nueva forma inacabada del sistema capitalista, causa desconcierto e incertidumbre precisamente porque, como dice Ricoeur (1990), cada forma de universalización "constituye una suerte de sutil destrucción, no sólo de las culturas tradicionales... sino también del núcleo creativo de las grandes culturas... el núcleo sobre cuya base interpretamos la vida...el núcleo ético y mítico de la humanidad" (Ricoeur, 1990). Este relativismo cultural conduce a la indiferencia y aleja al individuo, cada vez más, de un pensamiento capaz de poner en tela de juicio los límites impuestos, por el poder político y económico, al desarrollo de su capacidad crítica y de su expresión.

Por eso, no es un lujo, sino una necesidad, la defensa, sin paliativos, de una enseñanza pública que, siguiendo a Brückner, no obedezca a "criterios de rendimiento sino de dominio y difusión de los conocimientos". Por ello, al aprendizaje de "los saberes útiles" hay que sumar el de otras disciplinas "ligadas estrictamente al desarrollo personal". La enseñanza de las humanidades, entre otras, puede abrir la mente a otras realidades diferentes a la de uno mismo. "Es el mensaje de la escuela que nos da una doble lección de humildad y curiosidad" y mantiene la capacidad crítica del individuo. Eso precisamente es lo que despierta la animadversión de los poderes político y económico que la están mercantilizando. Hay que protegerla de la invasión de los intereses privados, de los "virus publicitarios y, en general, de la uniformidad, la amnesia y la estupidez, plagas actuales de la democracia de masas" (Brückner, 2002: 151)

Como decía, a principios del siglo XX, un actor y cantante estadounidense, activista por los derechos de los negros, cada generación ha de resolver sus problemas y, en estos momentos, la política y la economía dominantes ponen trabas a la calidad de la educación, única forma de creación de seres libres y responsables que puedan incidir sobre su entorno. Por eso, es necesario evitar que esa tarea quede en manos de los poderes político y económico pues, como diría G. Bernard Shaw, 'el cerebro de un necio puede convertir la filosofía en estupidez, la ciencia en superstición y el arte en pedantería'. 
Si la libertad de pensamiento y la libertad de expresión están en peligro, también lo está el corolario de esta última, al pasar de ser un derecho individual a un derecho colectivo, la libertad de prensa, amenazada por diversos factores mucho más sutiles que la censura previa.

\subsection{Límites a la libertad de expresión y, su corolario, la libertad de prensa}

Si las decisiones económicas y políticas condicionan, no sólo la estrategia de las empresas de medios de comunicación, sino también la práctica del periodismo ¿Se puede hablar de libertad de prensa?

Si el poder político puede conceder arbitrariamente licencias de explotación de medios de comunicación, subvenciones, inversión publicitaria institucional a las empresas de medios de comunicación ¿Se puede hablar de libertad de prensa?

Si hay competencia desigual por la diferencia de capacidad económica y financiera de las empresas, que desarrollan su actividad en la industria de medios de comunicación ¿Se puede hablar de libertad de prensa?

Si no hay independencia económica y financiera de los medios de comunicación ¿Se puede hablar de libertad de prensa?

$\mathrm{Si}$, por la precariedad laboral y de otros recursos, ha ido disminuyendo la información analítica, crítica y sustituyendo la información política y económica por declaraciones de políticos, gabinetes de prensa y comunicación de fuentes políticas y económicas interesadas iSe puede hablar de libertad de prensa?

Si se ha ido sustituyendo el debate con argumentos por tertulias espectáculo donde el más escuchado es el que más alza la voz ¿Se puede hablar de libertad de prensa?

Si se da prioridad a la información trivial y emocional, por ejemplo, la presentación de un jugador de fútbol, en detrimento del periodismo de investigación sobre casos políticos, económicos, interesantes socialmente para la transparencia democrática ¿Se puede hablar de libertad de prensa?

Si el periodismo deja de ejercer su función de control del poder político y económico, de guardián del derecho a la información y la libertad de expresión, como ingredientes fundamentales de la democracia, y se convierte en guardián de los intereses del poder, de los intereses empresariales ¿Se puede hablar de libertad de prensa?

Si se prescinde de los profesionales con más experiencia, a través de las prejubilaciones, puntales en sus respectivos medios y, a la vez, referente y fuente de credibilidad y de información y experiencia transmisible a los periodistas que empiezan a trabajar ¿Se puede hablar de libertad de prensa?

\section{Referencias bibliográficas}

BRÜCKNER, Pascal (2003): Miseria de la prosperidad. La religión del mercado y sus enemigos. Barcelona, Tusquets editores.

CHAMOUX, Jean Pierre (1994): Droit de la Communication. Paris, PUF, col. Que sais-je?.

CHYI, Hsiang Iris and CHANG, Hao-Chieh (2009): "Examining the use of and preference for online news in the context of intermedia competition". En: 
http://www.newmediaresarch.org/research/use-and-preference/ [Recuperado: 8 de junio de 2010].

CONESA SÁNCHEZ, Fernando (1978): La libertad de empresa periodística. Pamplona, Eunsa.

DE MATEO, Rosario; BERGÉS, Laura; y GARNATXE, Anna (2010): “Crisis ¿qué crisis? Los medios de comunicación: empresas y periodismo en tiempos de crisis", en CAMPOS FREIRE, Francisco (coord.): El cambio mediático. Sevilla-Zamora, Comunicación Social.

DE MATEO, Rosario y BERGÉS, Laura (2011): "El nuevo escenario mediático", en CAMPOS FREIRE, Francisco (ed,): El nuevo escenario mediático. Sevilla-Zamora, Comunicación Social.

FISS, Owen M. (1999): La ironía de la libertad de expresión. Barcelona, Gedisa.

BOURG, Dominique et BESNIER, Jean-Michel (2000): Peut-on encore croare au progrès?, PUF, 280s. Paris, La Politique éclatée.

PÁNIKER ALEMANY, Salvador (2014): Cuaderno Amarillo. Barcelona, Plaza y Janés.

RICOEUR, Paul (1990): “Civilización universal y culturas nacionales", en RICOEUR, Paul: Historia y Vida. Madrid, Ediciones Encuentro, pp. 41-54.

SMITH, Adam (2004): "La teoría de los sentimientos morales" [1759], en Filosofía. Madrid, Alianza.

WILLIAMS, Raymond (1974): Los medios de comunicación social. Barcelona, Ediciones Península, $2^{\mathrm{a}}$ edición. 